\title{
An economic-based estimation of irrigation water demand
}

\author{
U. Griessbach, P. Stange \& N. Schütze \\ Institute of Hydrology and Meteorology, TU Dresden, Germany
}

\begin{abstract}
Due to climate change, extreme weather conditions such as droughts may have an increasing impact on agriculture in Saxony (eastern Germany). For this reason, and additionally, expected increasing evapotranspiration during the growing season, the use of irrigation will be more important in the future. To cope with this higher demand for water, a new decision support framework is developed which focuses on an integrated management of both irrigation water supply and demand. For modeling the regional water demand, local (and site-specific) water demand functions are used which are derived from optimized agronomic response at farms scale. To account for climate variability the agronomic response is represented by stochastic crop water production functions (SCWPF). These functions take into account different soil types, crops and stochastically generated climate scenarios. The SCWPF's are used to compute the water demand considering different conditions, e.g., variable and fixed costs. This generic approach enables the consideration of both multiple crops at farm scale as well as of the aggregated response to water pricing at a regional scale for full and deficit irrigation systems. Within the SAPHIR (SAxonian Platform for High Performance IRrigation) project a prototype of a decision support system is developed which helps to evaluate combined water supply and demand management policies.

Keywords: irrigation, water demand, integrated water management.
\end{abstract}

\section{Introduction}

Currently, less than one percent of the Saxonian agricultural area is irrigated [1]. The main irrigated crops are potatoes and field vegetable like beans, spinach and peas. In the course of the climate change, an increase of temperature and a declining amount of rainfall during the growing season in Saxony are expected [2]. 
A more uneven distribution of rainfall leads to an increase of dry spells periods. Subsequently, the yield and yield stability of agricultural cultures could decrease. Especially the northern parts of Saxony are likely to be more drought-effected because of their sandy soils. This will lead to increased importance of irrigation as one form of risk management goes along with an increased water demand [2,3].

For farmers the use of irrigation depends largely on economical rentability. Yield is one of the main critical factors on profit. However, it's the factor that is the most difficult to estimate [4].

Decision-makers are focussed on regional scale. They want to estimate whether the possible future increasing demand of irrigation water can be covered by the future water supply. There are different political instruments to regulate the water demand. One of them is the water pricing policy because an increasing water price goes along with a decreasing rentability of irrigation and therefore with an increasing water demand [5]. The prerequisite for this is the knowledge of the water demand depending on the water price.

The goal of the Project SAPHIR (SAxonian Platform for High Performance IRrigation) is to develop methods to simulate the whole irrigation process, starting from soil and plant parameters up to the economic assessment. The focus is on development of high efficient irrigation systems to maximize the water saving potential, which includes the irrigation application method. In regions without water scarcity, it is common to use the full irrigation method, which means to meet the full crop water demand all over the growing season. The aim of the full irrigation is to maximize the crop yield. The deficit irrigation is a type of irrigation application method which maximizes the irrigation water productivity. This is achieved by a water restriction limited to drought-tolerant phenological stages, which minimizes crop yield losses [6].

\section{Computational aspects}

\subsection{Model description}

The modeling process can be divided into two main components. The first component is the so-called virtual field that represents all soil water and plant processes on field scale. The core of the virtual field is a physical and physiological based soil water and plant growth model which is calibrated and validated on field experiments. The use of a plant growth model allows for the spatial and temporal transferability. Stochastic aspects are generated from the weather generator LARSWG [7] and variable soil aspects. The plant growth model is the basis for optimization of the irrigation water distribution within the growing season using a special generic algorithm [8,9].

The second component of the modeling process is the decision support system for regional scale. It allows an determination of areas with the highest need for irrigation and yield security in Saxony as a base for an integrated water management system. 
Both components are connected through stochastic crop water production functions (SCWPF's) which describe the relationship between irrigation water and crop production (harvestable parts of the plants). From the virtual field we receive likelihood-dependent supporting points to generate the SCWPF's. For the purpose of upscaling the site-specific SCWPF from field experiments to whole Saxony we use up to five main soil types in a $5 \times 5 \mathrm{~km}$ grid and climate data from German Weather Service. The basis for the temporal transferability are future climate scenarios from different climate models such as WETTREG and WEREX [10]. The supporting points for generating SCWPF's are computed in the plant growth model for all these main soil types in consideration of site-specific weather data. The results are stored in a data base.

Data for the future water supply comes from the cooperation with the project KliWES, which is concerned with the effect of climate change on water balance in Saxony. The aim of this project is the categorization of Saxony's catchments into areas with similar levels of susceptibility to climate change under consideration of different land use and climate scenarios.

\subsection{SCWPF interpolation}

After modeling the plant growth, each SCWPF $Y$ is given as a number of sets $Y_{q}$ of $n$ discrete points $p_{q j}$, i.e.,

$$
Y_{q}=\left\{p_{q j}\right\}_{1 \leq j \leq n}
$$

Thereby each point $p_{q j}$ represents the yield subject to the amount of irrigated water with a yield certainty $q=\{0 \%, 25 \%, 50 \%, 75 \%, 95 \%\}$. For further computations we need first to use the set of these discrete points corresponding to the chosen yield certainty to generate a $w$-continuous CWPF $y(w)$, where $w$ represents the amount of irrigation water, $\mathrm{cf}$. (2). This is done by monotone piecewise cubic interpolation $[11,12]$. By using this technique we generate a continuous function with continuous first derivatives at the grid points that consists of cubic polynomials. This method doesn't lead to overshoots, which is important to avoid artificial extreme values. Figure 1 shows an example of a crop water production function with a yield certainty of $50 \%$. The dotted line represents the interpolated yield function when standard cubic splines are used. This method introduces an artificial maximum value of the gained yield for an irrigation amount of water between $50 \mathrm{~mm}$ and $100 \mathrm{~mm}$. Hence it isn't applicable for the following computations, which will be discussed below. By using monotone interpolation techniques these overshoots are avoided, as it is shown by the permanent line.

\subsection{Economic model parameters}

The economic calculation is based on a cost-benefit analysis. The benefits of irrigation are calculated from SCWPF's and the producer prices [13]. The cost calculation considers several types of irrigation systems like sprinkler, pivot, drip irrigation. This due to the fact that these systems differ from one another on crucial 


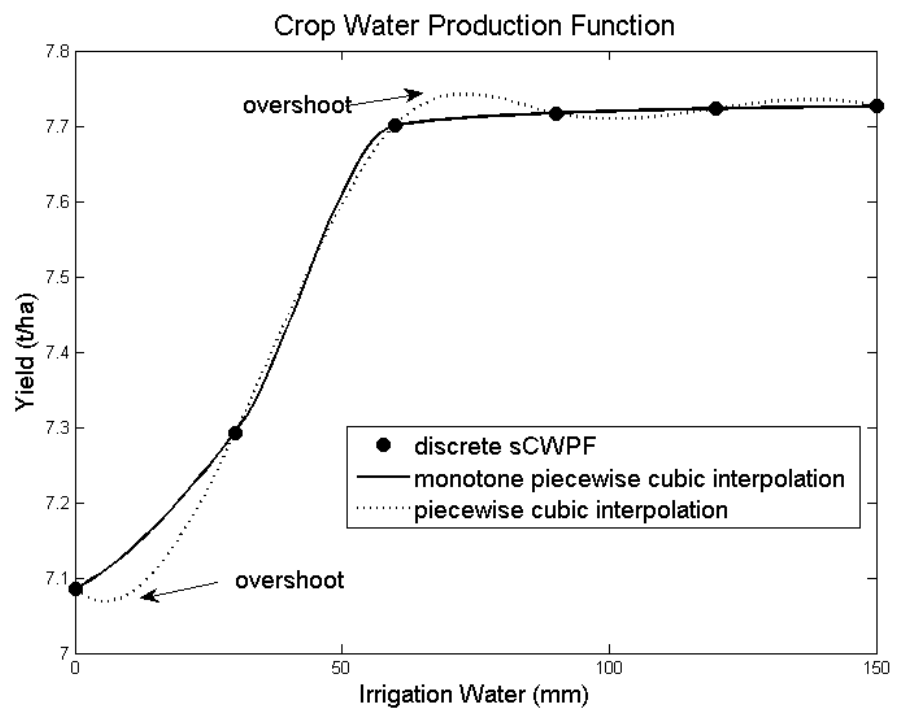

Figure 1: Spline comparison.

points, for example in irrigation efficiency, investment costs, suitability for special field sizes and geometry. In the first step the irrigation costs for several irrigation systems has been calculated on field scale. These costs are distinguished in fixed costs and variable costs. The variable costs (operation and maintenance costs) depend on the amount of irrigation water and they include energy, water, usual maintenance and labour costs. For calculations at regional scale the water costs have to be excluded to generate the demand function depending on the water price. The main part of the fixed costs are the investment costs which include costs for irrigation system, pumps, wells, pipelines and lines. These investment costs are distributed among the life expectancy of the irrigations system to obtain a fixed sum of costs per hectare in a year. Furthermore, the fixed costs include depending opportunity costs, maintenance and labour costs. The larger the field size the lower are the fixed costs per hectare. This applies to all systems. The input data for these calculations is derived from KTBL [14], which is based on interviews with dealers and irrigation experts. These data are modular, which allows for the calculation for different input parameters.

\subsection{Economic modeling and optimization}

The main goal is to maximize the profit due to irrigation which corresponds to the computation of the global maximum of the profit function

$$
P(w)=A \cdot\left(\left(y(w)-Y_{d}\right) \cdot P_{c}-\left(C_{v}+P_{w}\right) \cdot w-C_{f}\right),
$$


where

$$
\begin{aligned}
& y(w) \ldots \text { yield function, piecewise cubic, continuous } \\
& Y_{d} \ldots \text { dryland yield } \\
& A \ldots \text { planted area } \\
& P_{c} \ldots \text { producer price } \\
& P_{w} \ldots \text { water price } \\
& C_{v} \ldots \text { variable costs per unit water } \\
& C_{f} \ldots \text { fixed costs per unit area. }
\end{aligned}
$$

To determine the requested irrigation water for each crop, it is necessary to compute the global maximum of the corresponding profit function (2). That means in a first step we have to compute the roots $w_{i}^{*}$ of the first derivative of (2) which is defined as

$$
\frac{\mathrm{d} P(w)}{\mathrm{d} w}=A \cdot\left(P_{c} \cdot \frac{\mathrm{d} y(w)}{\mathrm{d} w}-\left(C_{v}+P_{w}\right)\right)
$$

where $\frac{\mathrm{d} y(w)}{\mathrm{d} w}$ is piecewise given by the derivatives of the single cubic splines of $y(w)$. For each of these roots, as well as for the amount of water which would be used in the case of full irrigation, we calculate the corresponding profit $P_{i}^{*}\left(w_{i}^{*}\right)$ by using equation (2). The maximum value of $P_{i}^{*}$ leads to the irrigation amount which is the most profitable considering the conditions shown in (2). The prescribed method can easily be extended to multiple SCWPF's. This offers the possibility to simulate the requested amount of water on a larger scale where different conditions prevail, e.g. different climate and soil conditions or different crops. In this case each of the SCWPF's can be regarded independently from the others. Finally, the total demand of water is given as the sum of the optimal amounts for each CWPF. This is possible as long as the amount of available water is larger than required for irrigation. Otherwise it is necessary to introduce an upper bound of available water for the single CWPF's. Basically this is done by reducing the sets shown in (1). Figure 2 shows a set of six different crop water production functions that was used for the water demand calculation shown in figure 3 . The values which are marked by ' $*$ ' represent the amounts of irrigation water which lead to the highest profit for each single CWPF. The total required water for irrigation is derived by summing up these values. There is no water demand for the crop which corresponds to the dotted line because the minimal profit of $50 \mathrm{EUR} /$ ha that is necessary for applying irrigation can not be reached in this case.

\subsection{Water demand function}

A demand function is a graph depicting the price-quantity relationship and is used to estimate the consumer behavior (4). In the diagram the water price is shown as a function of the demanded water volume. An increasing water price causes a 


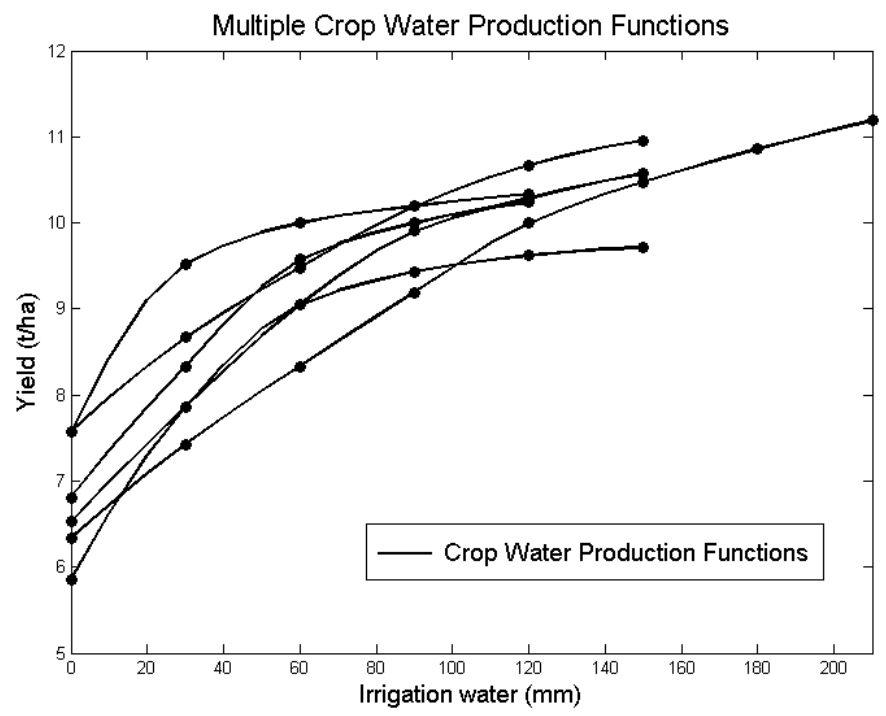

Figure 2: Multiple CWPF's.

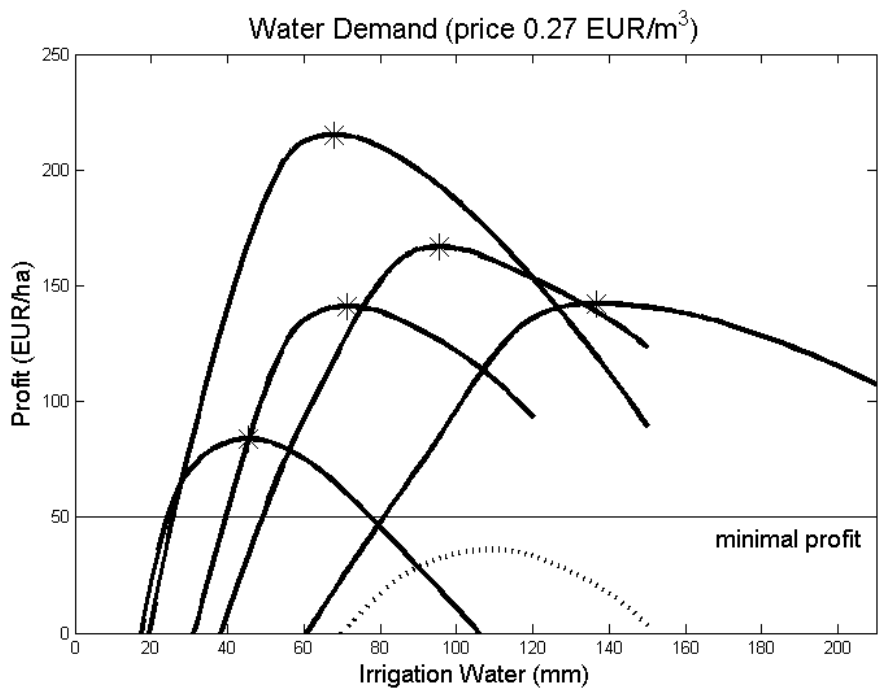

Figure 3: Profit functions for multiple CWPF's.

decreasing demand of irrigation water volume, because of the lower profitability of irrigation. From the economical point of view the farmer will respond to increasing water prices first with a reduced amount of irrigation water per hectare. If the profit (EUR/ha) decreases below a certain point, he will reduce the irrigated area. This behavior to optimize profit leads to abrupt changes in demand curve. Figure (4) 
shows the demand function of several individual CWPF's and their aggregation for a specific region like catchment or administrative area. This enables decisionmakers to estimate the amount of irrigation water subject to water price. The conceptual framework on regional scale will be included in a prototype of a decision support system. This allows for evaluation of combined water supply (from project KliWES [15]) and demand management policies for an effective and efficient utilization of water in order to meet future demands. The prototype is implemented as a web-based decision support system and it is based on a serviceoriented geo-database architecture.

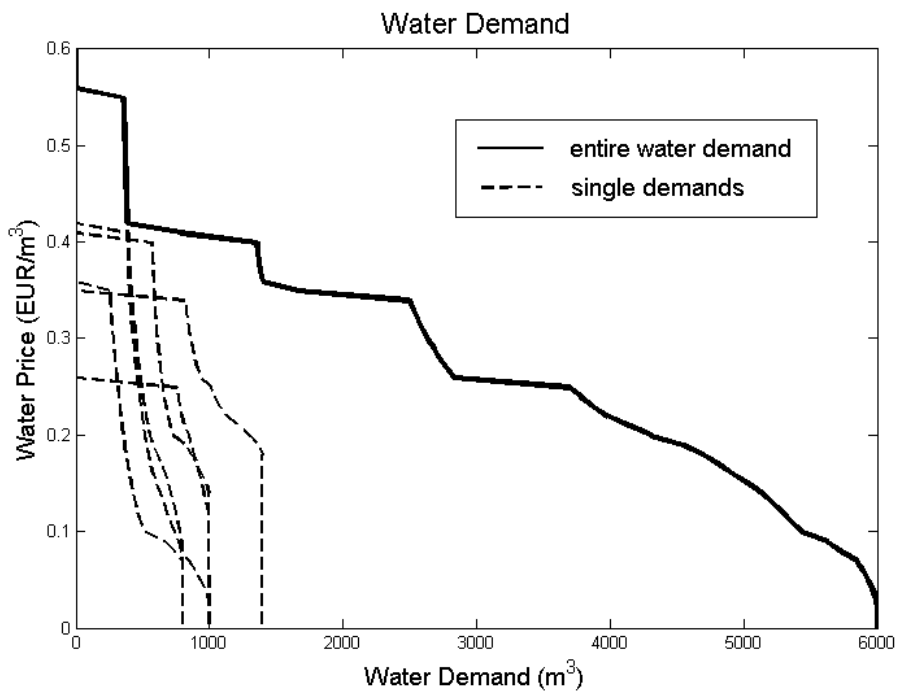

Figure 4: Aggregated water demand function.

\section{Conclusions}

Due to climate change an increasing irrigation water demand is expected in Saxony. For decision-makers this gives rise to new problems related to possible water scarcity. Within the project SAPHIR a method has been developed that combines the estimation of future irrigation water demand and supply. The approach is based on modeling on field scale with a plant growth model and optimization process which calculates supporting points for generating SCWPF's. The interface between calculations on field and on regional scale is a database with generated site-specific SCWPF's considering soil and climate variability and different crop parameters. Data from this database are used for generating 
a continuous crop growth function obtained by spline interpolation. From the economic point of view the main goal is to maximize the profit. Based on these spline functions the profit maximum is calculated by searching for extreme values considering the type of irrigation system. The amount of regional irrigation water demand is computed by aggregation water demand of each SCWPF subject to water price. The results will be processed in a prototype of a decision support system that helps decision makers in their decision processes. The described approach provides a base for further optimization processes considering different crops.

\section{References}

[1] Statistisches Bundesamt, Land- und Forstwirtschaft, Fischerei, Bodenbearbeitung, Bewässerung, Landschaftselemente - Erhebung über landwirtschaftliche Produktionsmethoden (ELPM). Technical report, Statistisches Bundesamt, 2011.

[2] Bernhofer, C., Goldberg, V. \& Franke, J., Sachsen im Klimawandel. Eine Analyse. Technical report, Staatsministerium für Umwelt und Landwirtschaft, 2008.

[3] Franke, J., Goldberg, V., Eichelmann, U., Freydank, E. \& Bernhofer, C., Statistical analysis of regional climate trends in Saxony, Germany. Climate Research, 27, pp. 145-150, 2004.

[4] Ewert, F., Rounsevell, M., Reginster, I., Metzger, M. \& Leemans, R., Future scenarios of European agricultural land use: I. Estimating changes in crop productivity. Agriculture, Ecosystems and Environment, 107, pp. 101-116, 2005.

[5] Bontemps, C. \& Couture, S., Irrigation water demand for the decision maker. Environment and Development Economics, 7, pp. 643-657, 2002.

[6] English, M., Deficit irrigation: I. Analytical framework. Journal of Irrigation and Drainage Engineering, 116(3), pp. 399-412, 1990.

[7] Semenov, M.A. \& Stratonovitch, P., Use of multi-model ensembles from global climate models for assessment of climate change impacts. Climate Research, 41, pp. 1-14, 2010.

[8] Schütze, N. \& Schmitz, G., Occasion: A new planning tool for optimal climate change adaption strategies in irrigation. Journal of Irrigation and Drainage Engineering, 136(12), pp. 836-846, 2010.

[9] Schütze, N., de Paly, M. \& Shamir, U., Novel simulation-based algorithms for optimal open-loop and closed-loop scheduling of deficit irrigation systems. Journal of Hydroinformatics, 14(1), pp. 136-151, 2012.

[10] Kreienkamp, F., Spekat, A. \& Enke, W., Ergebnisse regionaler Szenarienläufe für Deutschland mit der statistischen Methode WETTREG auf der Basis der SRES Szenarios A2 und B1 modelliert mit ECHAM5/MPI-OM. Technical report, Climate and Environment Consulting Potsdam GmbH, finanziert vom Climate Service Center, 2011. 
[11] Fritsch, F.N. \& Carlson, R.E., Monotone piecewise cubic interpolation. SIAM Journal on Numerical Analysis (SIAM), 17, pp. 238-246, 1980.

[12] de Boor, C., A Practical Guide to Splines. Springer-Verlag, 1978.

[13] Landesamt für Umwelt, Landwirtschaft und Geologie (LfULG), Datenbank Planungsrichtwerte, 2013.

[14] Kuratorium für Technik und Bauwesen in der Landwirtschaft e.V. (KTBL), KTBL- Datensammlung Freilandbewässerung - Betriebs- und arbeitswirtschaftliche Kalkulationen. KTBL, 2013.

[15] Landesamt für Umwelt, Landwirtschaft und Geologie (LfULG), KliWES Kernkomponente. LfULG, 2011. 